\title{
Structure of Sodium Gallotitanate Glass in Relation to Glass Formation
}

\author{
Fumiaki MIYAJI, Toshinobu YOKO* and Sumio SAKKA* \\ Division of Material Chemistry, Faculty of Engineering, Kyoto University, Yoshida-honmachi, Sakyo-ku, Kyoto-shi 606-01 \\ *Institute for Chemical Research, Kyoto University, Gokasho, Uji-shi, Kyoto 611
}

\author{
ガラス形成と関係したナトリウムガロチタン酸塩ガラスの構造 \\ 宮路史明・横尾俊信*。作花済夫* \\ 京都大学工学部材料化学教室, 606-01 京都市左京区吉田本町 \\ *京都大学化学研究所, 611 宇治市五ヶ庄
}

[Received October 25, 1993; Accepted December 15, 1993]

\begin{abstract}
The structure of $40 \mathrm{NaO}_{0.5} \cdot 20 \mathrm{GaO}_{1.5} \cdot 40 \mathrm{TiO}_{2}$ glass has been investigated by $\mathrm{X}$-12ay radial distribution analysis. Nearly all the $\mathrm{Ga}^{3+}$ and $\mathrm{Ti}^{4+}$ ions are four coordinated, constructing highly cross-linked three-dimensional glass networks, and that the number of non-bridging oxygens is very small. The degree of medium-range order in this glass is much lower than in the $\mathrm{Na}_{2} \mathrm{O} \cdot 2 \mathrm{TiO}_{2}$ gllass studied in a previous paper, possibly due to the almost complete alosence of $\mathrm{TiO}_{6}$ octahedra in the former glass. The higher glass-forming ability of the $\mathrm{Na}_{2} \mathrm{O}$ $\mathrm{Ga}_{2} \mathrm{O}_{3}-\mathrm{TiO}_{2}$ ternary system compared with the $\mathrm{Na}_{2} \mathrm{O}=$ $\mathrm{TiO}_{2}$ binary system is ascribed mainly to the higher fraction of four-coordinated $\mathrm{Ti}^{4+}$ ions in the former system. It is suggested that in oxide systems glass-form= ing ability increases with increasing fraction of fourcoordinated $\mathrm{Ti}^{4+}$ ions.
\end{abstract}

Key-words : Sodium gallotitanate glass, Structure, Glass formation, $X$-ray diffraction

\section{Introduction}

$\mathrm{Ga}_{2} \mathrm{O}_{3}$ or $\mathrm{TiO}_{2}$ does not form a glass by itself, but each oxide forms a binary glass when it is combined with certain alkali oxides. ${ }^{1)-4)}$ Kokubo et al. found that combination of alkali oxide, $\mathrm{Ga}_{2} \mathrm{O}_{3}$ and $\mathrm{TiO}_{2}$ gives pretty wide glass-forming regions, producing ternary alkali gallotitanate glasses. ${ }^{4)}$ The authors studied the structure ${ }^{5)}$ and electrical properties ${ }^{6)}$ of these glasses. Raman spectra of the glasses showed that most $\mathrm{Ga}^{3+}$ and $\mathrm{Ti}^{4+}$ ions are four coordinated and the $\mathrm{Ga}-\mathrm{O}$ and $\mathrm{Ti}-\mathrm{O}$ bond strength changes with glass composition.5) However, precise interatomic distances and coordination number of the cations in the glasses have not been given yet. In the present work, we aim at obtaining quantitative structural parameters and correlating the glass structure with glass formation in the system.

From the viewpoint of glass formation, the alkali gallotitanate system can be regarded as the modification of the alkali gallate or alkali titanate system. The authors already performed the X-ray radial distribution analyses on cesium gallate, ${ }^{7)}$ and sodium $^{8)}$ and potassium ${ }^{9}$ titanate glasses. Therefore, it is possible to compare the structure of alkali gallotitanate glasses with those of alkali gallate or alkali titanate glasses.

In the present work, we chose $40 \mathrm{NaO}_{0.5} \cdot 20 \mathrm{GaO}_{1.5}$. $40 \mathrm{TiO}_{2}$ glass as the target composition. First, this composition is chemically quite stable, suitable for long-time X-ray measurements. Second, the X-ray radial distribution analysis on $\mathrm{Na}_{2} \mathrm{O} \cdot 2 \mathrm{TiO}_{2}$ glass, which is a base composition of $40 \mathrm{NaO}_{0.5} \cdot 20 \mathrm{GaO}_{1.5}$. $40 \mathrm{TiO}_{2}$ glass, was carried out in the previous work. It was found that $\mathrm{Na}_{2} \mathrm{O} \cdot 2 \mathrm{TiO}_{2}$ glass contains a certain fraction of $\mathrm{TiO}_{6}$ octahedra in addition to predominant $\mathrm{TiO}_{4}$ tetrahedra. ${ }^{8)}$ In this study, the effect of addition of $\mathrm{Ga}_{2} \mathrm{O}_{3}$ on the structure around $\mathrm{Ti}^{4+}$ ions in the $\mathrm{Na}_{2} \mathrm{O} \cdot 2 \mathrm{TiO}_{2}$ glass will be examined and glass formation in these systems will be discussed based on the structural information obtained.

\section{Experimental}

\subsection{Sample preparation}

Glass of molar composition $40 \mathrm{NaO}_{0.5} \cdot 20 \mathrm{GaO}_{1.5}$. $40 \mathrm{TiO}_{2}$ was prepared by ordinary melt quenching method. A $10 \mathrm{~g}$ glass batch consisting of reagentgrade $\mathrm{Na}_{2} \mathrm{CO}_{3}, \mathrm{Ga}_{2} \mathrm{O}_{3}$ and $\mathrm{TiO}_{2}$ was melted in a platinum crucible in an electric furnace at $1550^{\circ} \mathrm{C}$ for 30 min. The melt was poured onto a brass plate and quickly pressed by another plate. A clear glass about $0.5 \mathrm{~mm}$ thick was obtained.

\section{$2.2 \mathrm{X}$-ray radial distribution analysis}

The X-ray scattering intensities were measured on fine glass powders prepared by pulverizing the thin glass sheets. A Rigaku Denki (Tokyo, Japan) model RINT 1200-S horizontal goniometer type X-ray diffractometer was employed. Mo $\mathrm{K} \alpha \quad(\lambda=0.709 \AA$ radiation was used as X-ray source. A Kevex (Stamford, CA) model P/N 7257-0000 Peltier cooled type $\mathrm{Si}(\mathrm{Li})$ solid state detector (SSD) was used as a photon detector.

The effect of Compton shift, $\Delta \lambda=h(1-\cos 2 \theta) /$ $m c$, cannot be neglected at higher scattering angle, since a part of inelastic Compton scattering is out of window set by a pair of ordinary $\mathrm{Zr}-\mathrm{Y}$ balanced filters at higher scattering angle. On the contrary, the SSD used in the present measurements can distinguish between elastic and inelastic scattering in- 
tensities, because energy window can be arbitrarily set. Especially, the SSD can be effective for the present glass consisting of relatively lighter elements such as oxygen, sodium, titanium and gallium, since the lower the atomic number, the larger the ratio of inelastic intensity to elastic intensity, making the collection of net intensities difficult.

The intensities were measured from 4 to $140^{\circ}$ in 2 $\theta$, corresponding to 0.6 to $16.6 \AA^{-1}$ in $S(=4 \pi \sin \theta$ / $\lambda$ ). The measurements were carried out by $400 \mathrm{~s}$ fixed-time counting method with step scanning at intervals of $0.5^{\circ}$ in $2 \theta$ and repeated until the accumulative intensities exceeded $5 \times 10^{5}$ counts at each point. The input power was set to $50 \mathrm{kV}-40 \mathrm{~mA}$. The average intensities at each angle was taken as the scattered X-ray intensity.

The intensity curve was normalized after being corrected for air scattering and polarization. The experimental amplitude function $S i(S)$ was calculated from the normalized intensity. Then the $S i(S)$ was transformed into the radial distribution function, RDF.

\section{Results}

The density of the glass measured by Archimedean method was $3.49 \mathrm{~g} \cdot \mathrm{cm}^{-3}$.

Figures 1 and 2 show the normalized X-ray intensity and the modified experimental amplitude function $\mathrm{Si}(S)$ curves, respectively. The oscillations in the curves continue up to $16.6 \AA^{-1}$. Figure 3 shows the RDF curve obtained by the Fourier transformation of $\operatorname{Si}(S)$, in which peaks are observed at 1.90 and $3.55 \AA$. Figure 4 shows the differential RDF curve. Clear peaks appear at $1.88,3.28$ and $4.58 \AA$ in the curve. The first peak overlaps with the large second peak.

The first peak at $1.88 \AA$ in the differential RDF curve can be interpreted as the nearly complete overlapping of the two peaks due to $\mathrm{GaO}_{4}$ and $\mathrm{TiO}_{4}{ }^{7}{ }^{7,9}$ )

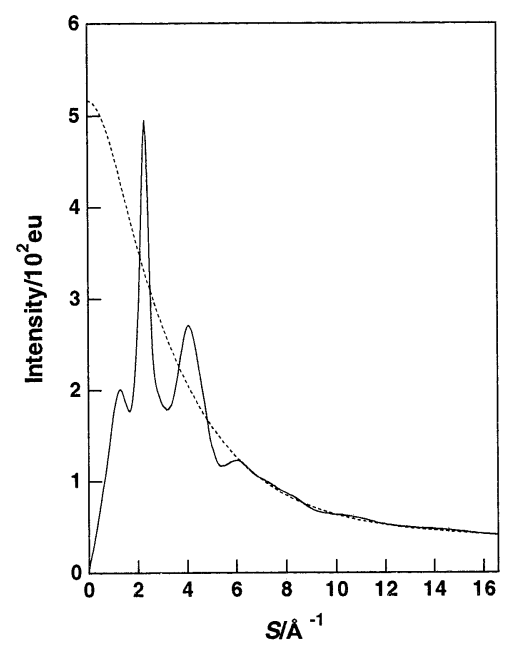

Fig. 1. X-ray diffraction intensity curves of $40 \mathrm{NaO}_{0.5} \cdot 20 \mathrm{GaO}_{1.5}$. $40 \mathrm{TiO}_{2}$ glass. The solid and broken lines denote the observed and theoretical intensity curves, respectively.

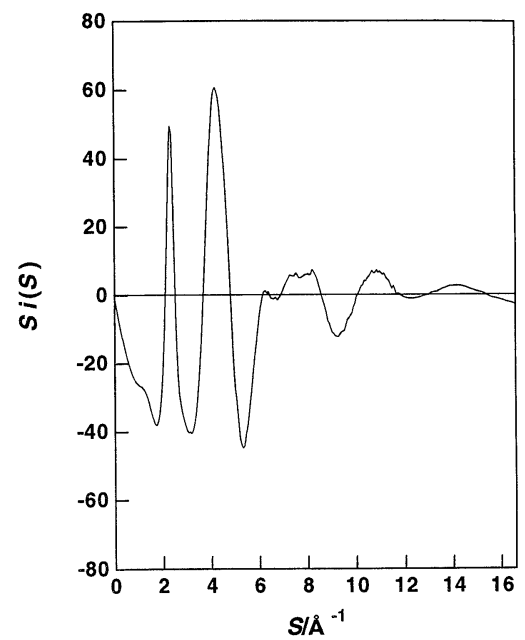

Fig. 2. Modified experimental amplitude function, $\operatorname{Si}(S)$, curve of $40 \mathrm{NaO}_{0.5} \cdot 20 \mathrm{GaO}_{1.5} \cdot 40 \mathrm{TiO}_{2}$ glass.

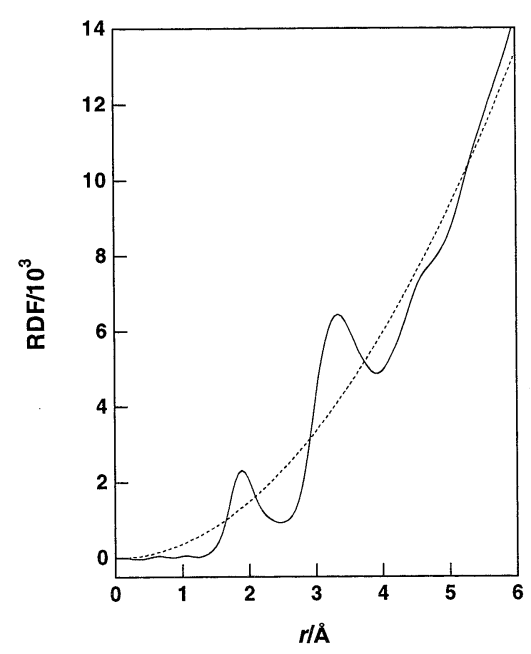

Fig. 3. RDF curves of $40 \mathrm{NaO}_{0.5} \cdot 20 \mathrm{GaO}_{1.5} \cdot 40 \mathrm{TiO}_{2}$ glass. The solid and broken lines denote the observed RDF and average density curves, respectively.

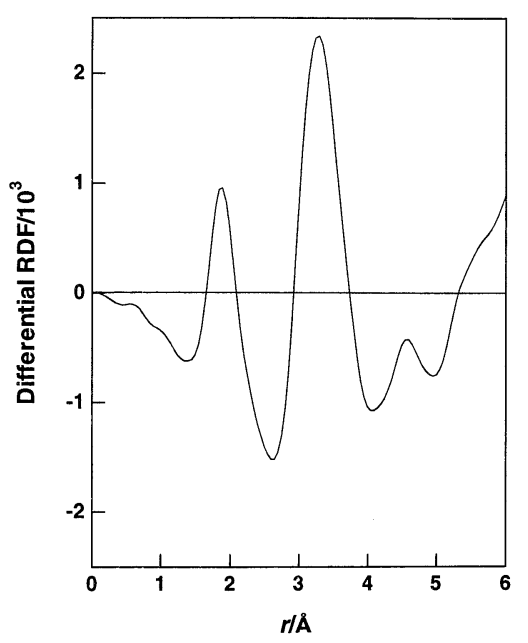

Fig. 4. Differential RDF curve of $40 \mathrm{NaO}_{0.5} \cdot 20 \mathrm{GaO}_{1.5} \cdot 40 \mathrm{TiO}_{2}$ glass. 


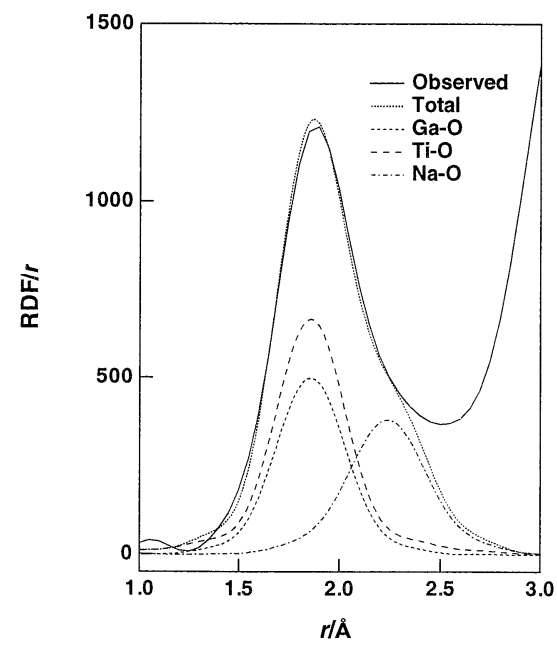

Fig. 5. Pair-function fitting curves for $40 \mathrm{NaO}_{0.5} \cdot 20 \mathrm{GaO}_{1.5}$. $40 \mathrm{TiO}_{2}$ glass.

Table 1. Optimized Parameters of Pair-Function Fitting for $40 \mathrm{NaO}_{0.5} \cdot 20 \mathrm{GaO}_{1.5} \cdot 40 \mathrm{TiO}_{2}$ Glass

\begin{tabular}{lcc}
\hline Pair & $\begin{array}{c}\text { Coordination } \\
\text { number }\end{array}$ & $\begin{array}{c}\text { Interatomic } \\
\text { distance/ } \AA\end{array}$ \\
\hline Ti-O & 4 & 1.86 \\
Ga-O & 4 & 1.86 \\
$\mathrm{Na}-\mathrm{O}$ & 6 & 2.24 \\
\hline
\end{tabular}

The peak corresponding to six-coordinated $\mathrm{Ga}^{3+}$ and $\mathrm{Ti}^{4+}$ ions is located at more remote distance than $1.95 \AA .{ }^{7), 8)}$ However, this is not the case.

The above assignments was examined by pairfunction fitting to the first peak. The optimized result of the fitting is shown in Fig. 5. The parameters obtained in the calculation are listed in Table 1. The calculated curve well fits to the observed curve. This result indicates that most of the $\mathrm{Ga}^{3+}$ and $\mathrm{Ti}^{4+}$ ions are predominantly four coordinated and the fraction of six-coordinated $\mathrm{Ga}^{3+}$ and $\mathrm{Ti}^{4+}$ ions should be small, if any.

\section{Discussion}

\subsection{Glass structure}

Table 2 compares the present glass with several alkali gallate and titanate glasses with respect to the coordination states of $\mathrm{Ga}^{3+}$ and $\mathrm{Ti}^{4+}$ ions. The coordination state around $\mathrm{Ga}^{3+}$ ions in the present glass is almost the same, that is four, as those in other $\mathrm{Ga}_{2} \mathrm{O}_{3}$-containing glasses. This implies that the local structure around $\mathrm{Ga}^{3+}$ ions in $\mathrm{Ga}_{2} \mathrm{O}_{3}$-containing glasses are less affected by other oxide components.

On the other hand, the coordination state of $\mathrm{Ti}^{4+}$ ions significantly changes with glass composition. In fact, a fair fraction of $\mathrm{Ti}^{4+}$ ions is present in the form of $\mathrm{TiO}_{6}$ in $\mathrm{Na}_{2} \mathrm{O} \cdot 2 \mathrm{TiO}_{2}$ glass, ${ }^{8)}$ while nearly all the $\mathrm{Ti}^{4+}$ ions are four coordinated in $\mathrm{K}_{2} \mathrm{O} \cdot 2 \mathrm{TiO}_{2}$ glass. ${ }^{9)}$ In the present glass, the addition of $\mathrm{Ga}_{2} \mathrm{O}_{3}$ to $\mathrm{Na}_{2} \mathrm{O}$. $2 \mathrm{TiO}_{2}$ composition results in a substantial change in the structure, that is, six-coordinated $\mathrm{Ti}^{4+}$ ions are
Table 2. Coordination of $\mathrm{Ti}^{4+}$ and $\mathrm{Ga}^{3+}$ Ions in Oxide Glasses

\begin{tabular}{|c|c|c|c|c|c|}
\hline Glass & Method & Pair & $C N$ & $d / \AA$ & Ref. \\
\hline $40 \mathrm{NaO}_{0.5} \cdot 20 \mathrm{GaO}_{1.5} \cdot 40 \mathrm{TiO}_{2}$ & $\mathrm{X}$-ray & $\begin{array}{l}\text { Ti-O } \\
\text { Ga-O }\end{array}$ & $\begin{array}{l}4 \\
4\end{array}$ & $\begin{array}{l}1.86 \\
1.86\end{array}$ & $\begin{array}{l}\text { This } \\
\text { work }\end{array}$ \\
\hline $\mathrm{Na}_{2} \mathrm{O} \cdot 2 \mathrm{TiO}_{2}$ & $\mathrm{X}$-ray & Ti-O & $4+6$ & $1.99^{*}$ & 8) \\
\hline $\mathrm{K}_{2} \mathrm{O} \cdot 2 \mathrm{TiO}_{2}$ & $\mathrm{X}$-ray & Ti-O & 4 & 1.88 & 9) \\
\hline $10 \mathrm{Na}_{2} \mathrm{O} \cdot 70 \mathrm{SiO}_{2} \cdot 20 \mathrm{TiO}_{2}$ & Neutron & $\begin{array}{l}\text { Ti-O } \\
\text { Ti-O }\end{array}$ & $\begin{array}{l}4 \\
6\end{array}$ & $\begin{array}{l}1.85 \\
1.95\end{array}$ & 10) \\
\hline $30 \mathrm{Cs}_{2} \mathrm{O} \cdot 70 \mathrm{Ga}_{2} \mathrm{O}_{3}$ & $\mathrm{X}$-ray & $\mathrm{Ga}-\mathrm{O}$ & 4 & 1.87 & 7) \\
\hline $66.7 \mathrm{CaO} \cdot 33.3 \mathrm{Ga}_{2} \mathrm{O}_{3}$ & $\mathrm{X}$-ray & $\mathrm{Ga}-\mathrm{O}$ & 4 & 1.84 & 7) \\
\hline $50 \mathrm{PbO} \cdot 50 \mathrm{GaO}_{15}$ & Neutron & $\mathrm{Ga}-\mathrm{O}$ & 4 & 1.86 & 11) \\
\hline $80 \mathrm{BiO}_{15} \cdot 20 \mathrm{GaO}_{15}$ & Neutron & $\mathrm{Ga}-\mathrm{O}$ & 4 & 1.87 & 11) \\
\hline
\end{tabular}

no longer present.

The heaviest Ga-Ga pairs make a greatest contribution to the large second peak observed at about $3.3 \AA$ in Fig. 4. In fact, it has been reported that the peak at about $3.3 \AA$ in the $\mathrm{RDF}$ curve of $30 \mathrm{Cs}_{2} \mathrm{O}$. $70 \mathrm{Ga}_{2} \mathrm{O}_{3}$ glass corresponds to $\mathrm{Ga}-\mathrm{Ga}$ pairs. ${ }^{7)}$ Considering that the $\mathrm{Ga}-\mathrm{O}$ and $\mathrm{Ti}-\mathrm{O}$ distances in oxygen tetrahedra are almost the same, the nearest $\mathrm{Ti}-\mathrm{Ti}$ distance is assumed to equal the nearest $\mathrm{Ga}-\mathrm{Ga}$ distance. Therefore, $\mathrm{Ti}-\mathrm{Ti}$ pairs are also responsible for the peak. It should be mentioned here that in the case of $\mathrm{Na}_{2} \mathrm{O} \cdot 2 \mathrm{TiO}_{2}$ glass, the second peak at about $3.2 \AA$ overlaps with a clear shoulder at about $3.7 \AA$, indicating the coexistence of two kinds of structural units, $\mathrm{TiO}_{4}$ and $\mathrm{TiO}_{6}$.

The peak at $4.58 \AA$ is much smaller than the corresponding peak at $4.68 \AA$ in $\mathrm{Na}_{2} \mathrm{O} \cdot 2 \mathrm{TiO}_{2}$ glass. ${ }^{8)}$ This peak mainly reflects the $\mathrm{M}-\mathrm{O}(\mathrm{M}=\mathrm{Ti}$ or $\mathrm{Ga})$ next nearest pairs. The diminished peak in the present glass suggests that the $\mathrm{MO}_{4}$ tetrahedra are more randomly linked to each other and the distribution of $\mathrm{M}-\mathrm{O}-\mathrm{M}$ angles are widespread compared with $\mathrm{Na}_{2} \mathrm{O} \cdot 2 \mathrm{TiO}_{2}$ glass. In addition, no clear peaks appear in the RDF curve in the region longer than $5 \AA$ which reflects medium-range order. This result is different from that for $\mathrm{Na}_{2} \mathrm{O} \cdot 2 \mathrm{TiO}_{2}$ glass in which the RDF curve shows a distinct peak at $5.48 \AA .{ }^{8)}$ The lack of medium-range order in $40 \mathrm{NaO}_{0.5} \cdot 20 \mathrm{GaO}_{1.5}$. $40 \mathrm{TiO}_{2}$ glass in contrast with $\mathrm{Na}_{2} \mathrm{O} \cdot 2 \mathrm{TiO}_{2}$ glass is attributed to the almost complete absence of $\mathrm{TiO}_{6}$ octahedra in the former glass. This is also the case for the comparison of $\mathrm{K}_{2} \mathrm{O} \cdot 2 \mathrm{TiO}_{2}$ glass with $\mathrm{Na}_{2} \mathrm{O}$. $2 \mathrm{TiO}_{2}$ glass. ${ }^{8), 9)} \mathrm{Na}_{2} \mathrm{O} \cdot 2 \mathrm{TiO}_{2}$ glass containing a fair concentration of $\mathrm{TiO}_{6}$ octahedra retains a higher medium-range order than $\mathrm{K}_{2} \mathrm{O} \cdot 2 \mathrm{TiO}_{2}$ glass consisting only of $\mathrm{TiO}_{4}$ tetrahedra.

The most remarkable difference in environments of $\mathrm{Ga}^{3+}$ and $\mathrm{Ti}^{4+}$ ions consists in a way of charge compensation of $\mathrm{GaO}_{4}$ and $\mathrm{TiO}_{4}$ tetrahedra. Even if all the oxygens in $\mathrm{GaO}_{4}$ tetrahedron are bridging, excess negative charge is produced around the tetrahedron. This requires that at least one $\mathrm{Na}^{+}$ion is lo- 
cated near one $\mathrm{GaO}_{4}$ tetrahedron in order to compensate the excess negative charge. In contrast, the charge balance of $\mathrm{a} \mathrm{TiO}_{4}$ tetrahedron is retained if all the oxygens in the tetrahedron are bridging. It is only when $\mathrm{TiO}_{4}$ tetrahedron has a non-bridging oxygen that an $\mathrm{Na}^{+}$ion is forced to be adjacent to it. It is assumed that a part of $\mathrm{GaO}_{4}$ tetrahedra contain nonbridging oxygens in $\mathrm{Na}_{2} \mathrm{O}-\mathrm{Ga}_{2} \mathrm{O}_{3}-\mathrm{TiO}_{2}$ glasses; the strong stretching vibration of $\mathrm{GaO}_{4}$ tetrahedra containing non-bridging oxygens is observed in the Raman spectra of the glasses. ${ }^{5)}$ Also, Ti-O (non-bridging) vibration appears in the Raman spectra of alkali titanate glass. ${ }^{12)}$ These indicate that non-bridging oxygens may be present in both $\mathrm{GaO}_{4}$ and $\mathrm{TiO}_{4}$ tetrahedra in the present glass. The total fraction of nonbridging oxygen calculated from the glass composition is, however, as low as $7.7 \%$, indicating that the present glass consists of highly cross-linked threedimensional glass network. A simple structural model proposed for the present $40 \mathrm{NaO}_{0.5} \cdot 20 \mathrm{GaO}_{1.5}$. $40 \mathrm{TiO}_{2}$ glass is shown in Fig. 6.

If one assumes that $\mathrm{GaO}_{4}$ tetrahedra in the present glass should form clusters as in $\mathrm{PbO}-\mathrm{Ga}_{2} \mathrm{O}_{3}$ and $\mathrm{Bi}_{2} \mathrm{O}_{3}-\mathrm{Ga}_{2} \mathrm{O}_{3}$ glasses, ${ }^{11)} \mathrm{Na}^{+}$ions would be concentrated around the $\mathrm{Ga}-\mathrm{O}$ network because at least one $\mathrm{Na}^{+}$ion is located near one $\mathrm{GaO}_{4}$ tetrahedron as stated in the above. However, such aggregation of $\mathrm{Na}^{+}$ ions may be unfavorable for glass formation, since the ionic field strength for the $\mathrm{Ga}-\mathrm{O}$ network by $\mathrm{Na}^{+}$ ions is assumed to increase. It is rather favorable for glass formation that $\mathrm{GaO}_{4}$ and $\mathrm{TiO}_{4}$ tetrahedra are linked more randomly as shown in Fig. 6 in order to disperse the $\mathrm{Na}^{+}$ions. In this sense, similar coordination states of $\mathrm{Ga}^{3+}$ and $\mathrm{Ti}^{4+}$ ions, which will be discussed later, can be advantageous for random linkage of $\mathrm{GaO}_{4}$ and $\mathrm{TiO}_{4}$ tetrahedra.

In the $\mathrm{PbO}-\mathrm{Bi}_{2} \mathrm{O}_{3}-\mathrm{Ga}_{2} \mathrm{O}_{3}$ glasses, it was found that a large fraction of oxygens bonded to $\mathrm{Ga}^{3+}$ ions are three coordinated because of the serious shortage of oxygens for $\mathrm{Ga}^{3+}$ ions to form $\mathrm{GaO}_{4}$ tetrahedra. ${ }^{11}$

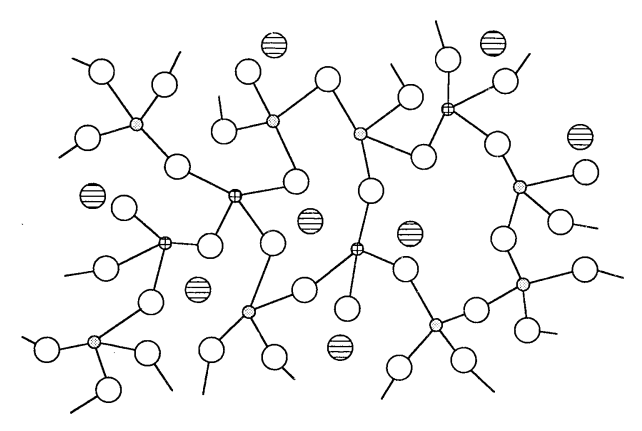

$$
\begin{aligned}
& \odot \mathrm{Ti} \\
& \oplus \mathrm{Ga} \\
& \bigcirc \mathrm{O} \\
& \ominus \mathrm{Na}
\end{aligned}
$$

Fig. 6. Simplified structural model of $40 \mathrm{NaO}_{0.5} \cdot 20 \mathrm{GaO}_{1.5}$. $40 \mathrm{TiO}_{2}$ glass.
On the other hand, in $\mathrm{RO}_{0.5}-\mathrm{GaO}_{1.5} \quad(\mathrm{R}=$ alkali metal) binary glasses three-coordinated oxygens are present at only the compositional region $\mathrm{RO}_{0.5} /$ $\mathrm{GaO}_{1.5}<1.5 .{ }^{13)}$ Taking into account the fact that $\mathrm{NaO}_{0.5} / \mathrm{GaO}_{1.5}$ ratio is 2 in the present glass, the fraction of three-coordinated oxygens should be low in the glass, if any. That is, in the present glass the three-coordinated oxygens are not needed, since sufficient number of oxygens for $\mathrm{Ga}^{3+}$ ions are present.

\subsection{Glass formation}

It has been reported that in the binary alkali titanate systems the higher the fraction of four-coordinated $\mathrm{Ti}^{4+}$ ions, the larger the glass-forming tendency. ${ }^{8), 12)}$ That is, glass-forming ability increases in the order $\mathrm{Na}_{2} \mathrm{O}-\mathrm{TiO}_{2}<\mathrm{K}_{2} \mathrm{O}-\mathrm{TiO}_{2}<\mathrm{Cs}_{2} \mathrm{O}-$ $\mathrm{TiO}_{2}$, which is parallel to the order of fraction of four-coordinated $\mathrm{Ti}^{4+}$ ions. This criterion can be extended to the ternary titanate systems. While the $\mathrm{Na}_{2} \mathrm{O}-\mathrm{TiO}_{2}$ binary system does not form a glass by ordinary melt quenching with metal plate, ${ }^{8)}$ the $\mathrm{Na}_{2} \mathrm{O}-\mathrm{Ga}_{2} \mathrm{O}_{3}-\mathrm{TiO}_{2}$ ternary system forms a glass in the considerably wide composition region by that technique. As indicated in the Section 4.1, the fraction of $\mathrm{TiO}_{6}$ octahedra in the present glass is very low, although small vibration peaks due to $\mathrm{TiO}_{6}$ octahedra were found in the Raman spectra of alkali gallotitanate glasses. ${ }^{5)}$ Considering that the glass-forming ability increases in the order $\mathrm{Na}_{2} \mathrm{O}-\mathrm{Ga}_{2} \mathrm{O}_{3}-\mathrm{TiO}_{2}$ $<\mathrm{K}_{2} \mathrm{O}-\mathrm{Ga}_{2} \mathrm{O}_{3}-\mathrm{TiO}_{2}<\mathrm{Cs}_{2} \mathrm{O}-\mathrm{Ga}_{2} \mathrm{O}_{3}-\mathrm{TiO}_{2}$, nearly all the $\mathrm{Ti}^{4+}$ ions in $\mathrm{K}_{2} \mathrm{O}-\mathrm{Ga}_{2} \mathrm{O}_{3}-\mathrm{TiO}_{2}$ and $\mathrm{Cs}_{2} \mathrm{O}-\mathrm{Ga}_{2} \mathrm{O}_{3}-$ $\mathrm{TiO}_{2}$ glasses are expected to take also four coordination as in the present glass. Consequently, it can be said that in oxide systems the variation in glass-forming tendency is parallel to fraction of four-coordinated $\mathrm{Ti}^{4+}$ ions.

In the $\mathrm{R}_{2} \mathrm{O}-\mathrm{Ga}_{2} \mathrm{O}_{3}-\mathrm{TiO}_{2}(\mathrm{R}=\mathrm{Na}, \mathrm{K}, \mathrm{Cs})$ ternary systems the glass-forming regions symmetrically spread around the central line corresponding to $\mathrm{Ga} /$ $\mathrm{Ti}=1$ in the triangular composition diagram. ${ }^{4)}$ This fact suggests that both $\mathrm{Ga}^{3+}$ and $\mathrm{Ti}^{4+}$ ions equally contribute to glass formation, participating in the construction of glass network in these glasses. This may be ascribed to the similarity of local structure around $\mathrm{Ga}^{3+}$ and $\mathrm{Ti}^{4+}$ ions. That is, the $\mathrm{Ga}-\mathrm{O}$ and Ti-O interatomic distances are the same at about $1.85 \AA$ and the oxygen coordination numbers are nearly four for both ions. It is well understood that the short-range structures of both ions are similar, because both ions have a resemblance to each other in several physicochemical properties; valence $(\mathrm{Ga}$ : +3 , $\mathrm{Ti}:+4)$, ionic radius $(\mathrm{Ga}: 0.47 \AA \mathrm{Ti}: 0.42$ $\AA)^{14)}$ and electronegativity ( $\left.\left.\mathrm{Ga}: 1.5, \mathrm{Ti}: 1.6\right) .{ }^{15}\right)$

Kokubo et al. examined the glass-forming regions in the $\mathrm{R}_{2} \mathrm{O}-\mathrm{Ga}_{2} \mathrm{O}_{3}-\mathrm{Nb}_{2} \mathrm{O}_{5}{ }^{2}$ and $\left.\mathrm{R}_{2} \mathrm{O}-\mathrm{Ga}_{2} \mathrm{O}_{3}-\mathrm{Ta}_{2} \mathrm{O}_{5}{ }^{3}\right)$ systems. The glass-forming regions are apparently narrower in these systems than in the $\mathrm{R}_{2} \mathrm{O}-\mathrm{Ga}_{2} \mathrm{O}_{3}-$ $\mathrm{TiO}_{2}$ system and spread to the $\mathrm{Ga} /(\mathrm{Nb}, \mathrm{Ta})>1$ composition. $\mathrm{Nb}^{5+}$ and $\mathrm{Ta}^{5+}$ ions are assumed to take six 
coordination in the glasses, ${ }^{2), 3)}$ which makes glass formation more difficult compared to the $\mathrm{R}_{2} \mathrm{O}-\mathrm{Ga}_{2} \mathrm{O}_{3}$ $\mathrm{TiO}_{2}$ system. In other words, glass-forming ability of the $\mathrm{TiO}_{2}$-containing systems is much larger than that of the $\mathrm{Nb}_{2} \mathrm{O}_{5}$ - or $\mathrm{Ta}_{2} \mathrm{O}_{5}$-containing systems because $\mathrm{Ti}^{4+}$ ions preferentially take four coordination in the glasses.

$\mathrm{Ga}_{2} \mathrm{O}_{3}$ can form a glass when it combined with either typical network modifiers, such as alkali and alkaline earth oxides, or heavy-metal oxides such as $\mathrm{PbO}$ or $\mathrm{Bi}_{2} \mathrm{O}_{3}$. On the other hand, $\mathrm{TiO}_{2}$ forms a glass not with $\mathrm{PbO}$ and $\mathrm{Bi}_{2} \mathrm{O}_{3}$ but with alkali or alkaline earth oxides, and $\mathrm{PbO}$ or $\mathrm{Bi}_{2} \mathrm{O}_{3}$ does not form a glass with alkali or alkaline earth oxides. From this point of view, $\mathrm{Ga}_{2} \mathrm{O}_{3}$ has a considerably high glass-forming ability among the above mentioned intermediates. This may be first attributed to the amphoteric nature of $\mathrm{Ga}_{2} \mathrm{O}_{3} ; \mathrm{Ga}_{2} \mathrm{O}_{3}$ has an affinity for both acidic and basic oxides and may form a homogeneous glass melt. Second, $\mathrm{Ga}^{3+}$ ions preferentially take four coordination in oxide glasses, and this is favorable for glass formation. Third, the oxygens bonded to $\mathrm{Ga}^{3+}$ ions have a tendency to take three coordination to accommodate the shortage of oxygens when the number of oxygens in the system are insufficient for $\mathrm{Ga}^{3+}$ ions to form $\mathrm{GaO}_{4}$ tetrahedra. ${ }^{11)}$

\section{Conclusion}

The structure of $40 \mathrm{NaO}_{0.5} \cdot 20 \mathrm{GaO}_{1.5} \cdot 40 \mathrm{TiO}_{2}$ glass was examined by $\mathrm{X}$-ray radial distribution analysis and the structure and ease of glass formation were discussed by comparing with $\mathrm{Na}_{2} \mathrm{O} \cdot 2 \mathrm{TiO}_{2}$ glass.

(1) The present glass can be prepared by ordinary melt-quenching technique. X-ray radial distribution analysis shows that nearly all the $\mathrm{Ga}^{3+}$ and $\mathrm{Ti}^{4+}$ ions are four coordinated and the medium-range order is low in the present glass.

(2) The lower medium-range order in the present glass than in the $\mathrm{Na}_{2} \mathrm{O} \cdot 2 \mathrm{TiO}_{2}$ glass is attributed to the almost complete absence of $\mathrm{TiO}_{6}$ octahedra in the former glass.

(3) The higher glass-forming ability of the
$\mathrm{Na}_{2} \mathrm{O}-\mathrm{Ga}_{2} \mathrm{O}_{3}-\mathrm{TiO}_{2}$ ternary system compared with the $\mathrm{Na}_{2} \mathrm{O}-\mathrm{TiO}_{2}$ binary system is ascribed to the higher fraction of four-coordinated $\mathrm{Ti}^{4+}$ ions in the former system.

(4) Glass-forming ability of the titanate systems increases as fraction of four-coordinated $\mathrm{Ti}^{4+}$ ions increases; $\mathrm{Na}_{2} \mathrm{O}-\mathrm{TiO}_{2}<\mathrm{K}_{2} \mathrm{O}-\mathrm{TiO}_{2}<\mathrm{Cs}_{2} \mathrm{O}-\mathrm{TiO}_{2}$ and $\mathrm{Na}_{2} \mathrm{O}-\mathrm{Ga}_{2} \mathrm{O}_{3}-\mathrm{TiO}_{2}<\mathrm{K}_{2} \mathrm{O}-\mathrm{Ga}_{2} \mathrm{O}_{3}-\mathrm{TiO}_{2}<\mathrm{Cs}_{2} \mathrm{O}-\mathrm{Ga}_{2} \mathrm{O}_{3}-$ $\mathrm{TiO}_{2}$. It is suggested that in oxide systems the variation in glass-forming tendency is parallel to fraction of four-coordinated $\mathrm{Ti}^{4+}$ ions.

Acknowledgment Supported by Grant-in-Aid No. 02403016 and 04453070 for Scientific Research from the Ministry of Education, Science and Culture, Japan.

\section{References}

1) H. Rawson, "Inorganic Glass-Forming Systems", Academic Press, London (1967) p. 201.

2) T. Kokubo, Y. Inaka and S. Sakka, J. Non-Cryst. Solids, 80, 518-26 (1986)

3) T. Kokubo, Y. Inaka and S. Sakka, J. Non-Cryst. Solids, 81, 337-50 (1987).

4) T. Kokubo, Y. Inaka and S. Sakka, J. Non-Cryst. Solids, 9596, 547-54 (1987)

5) F. Miyaji and S. Sakka, Seramikkusu Ronbunshi, 97, 267-73 (1987).

6) F. Miyaji, S. Hasegawa, T. Yoko and S. Sakka, J. Am. Cer am. Soc., 76, 545-46 (1993).

7) K. Fukumi and S. Sakka, J. Non-Cryst. Solids, 95-96, 193200 (1987)

8) F. Miyaji, T. Yoko, H. Kozuka and S. Sakka, J. Mater. Sci., 26, 248-52 (1991).

9) S. Sakka, F. Miyaji and K. Fukumi, J. Non-Cryst. Solids, 107, 171-77 (1989).

10) H. Hidaka, N. Iwamoto, N. Umesaki, T. Fukunaga and K. Suzuki, J. Mater. Sci., 20, 2497-502 (1985).

11) F. Miyaji, T. Yoko, Jisun Jin, S. Sakka, T. Fukunaga and M. Misawa, J. Non-Cryst. Solids, submitted to.

12) S. Sakka, F. Miyaji and K. Fukumi, J. Non-Cryst. Solids, 112, 64-68 (1989).

13) K. Fukumi and S. Sakka, Phys. Chem. Glasses, 29, 1-8 (1988).

14) R. D. Shannon, Acta Cryst., A32, 751-67 (1976).

15) W. Gordy and W. J. Orville-Thomas, J. Chem. Phys., 41, 3199-204 (1956). 